University of New Hampshire

University of New Hampshire Scholars' Repository

Faculty Publications

7-20-1993

\title{
Greenland ice core "signal" characteristics: An expanded view of climate change
}

\author{
Paul A. Mayewski \\ University of Maine \\ L. David Meeker \\ University of New Hampshire, Durham \\ Michael C. Morrison \\ University of New Hampshire, Durham \\ Mark S. Twickler \\ University of New Hampshire, Durham, mark.twickler@unh.edu \\ Sallie I. Whitlow \\ University of New Hampshire, Durham
}

See next page for additional authors

Follow this and additional works at: https://scholars.unh.edu/faculty_pubs

Comments

This is an article published by AGU in Journal of Geophysical Research: Atmospheres in 1993, available online:

https://dx.doi.org/10.1029/93JD01085

\section{Recommended Citation}

Mayewski, P. A., Meeker, L. D., Morrison, M. C., Twickler, M. S., Whitlow, S. I., Ferland, K. K., .. Steffensen, J. P. (1993). Greenland ice core "signal" characteristics: An expanded view of climate change. Journal of Geophysical Research, 98(D7), 12839. doi:10.1029/93JD01085

This Article is brought to you for free and open access by University of New Hampshire Scholars' Repository. It has been accepted for inclusion in Faculty Publications by an authorized administrator of University of New Hampshire Scholars' Repository. For more information, please contact Scholarly.Communication@unh.edu. 


\section{Authors}

Paul A. Mayewski, L. David Meeker, Michael C. Morrison, Mark S. Twickler, Sallie I. Whitlow, Kevin K.

Ferland, Debra A. Meese, M. R. Legrand, and J. P. Steffensen 


\title{
Greenland Ice Core "Signal" Characteristics: An Expanded View of Climate Change
}

\author{
P. A. Mayewski, ${ }^{1}$ L. D. Meeker, ${ }^{1,2}$ M. C. Morrison, ${ }^{1}$ M. S. Twickler, ${ }^{1}$ S. I. Whitlow, ${ }^{1}$ K. K. Ferland, ${ }^{1,2}$ D. A. \\ Meese, ${ }^{3}$ M. R. Legrand, ${ }^{4}$ and J. P. Steffensen ${ }^{5}$
}

\begin{abstract}
The last millenium of Earth history is of particular interest because it documents the environmental complexities of both natural variability and anthropogenic activity. We have analyzed the major ions contained in the Greenland Ice Sheet Project 2 (GISP 2) ice core from the present to 674 A.D. to yield an environmental reconstruction for this period that includes a description of nitrogen and sulfur cycling, volcanic emissions, sea salt and terrestrial influences. We have adapted and extended mathematical procedures for extracting sporadic (e.g., volcanic) events, secular trends, and periodicities found in the data sets. Finally, by not assuming that periodic components (signals) were "stationary" and by utilizing evolutionary spectral analysis, we were able to reveal periodic processes in the climate system which change in frequency, "turn on," and "turn off" with other climate transitions such as "that between the little ice age and the medieval warm period.
\end{abstract}

\section{Introduction}

Understanding the climate system remains one of the major intellectual challenges faced by science. The processes controlling climate and the resultant responses are complex (e.g., nonlinear, stationary, and nonstationary) and often only interpretable from the perspective of paleorecords since modern climate processes may be markedly affected by anthropogenic influences. To understand these complexities, we examine high resolution, continuous paleorecords utilizing an innovative form of environmental signal analysis that is particularly well suited to the interpretation of such series.

Time series for six chemical species were recovered from the first $310 \mathrm{~m}$ of the Greenland Ice Sheet Project 2 (GISP 2) deep core collected in the summit region of central Greenland ( $72^{\circ} 35^{\prime} \mathrm{N}$ latitude, $38^{\circ} 28^{\prime} \mathrm{W}$ longitude, elevation $3210 \mathrm{~m}$ above sea level). They provide insight into nitrogen cycling (via nitrate and ammonium), sulfur cycling (via non-sea-salt (nss) sulfate), volcanic source influences (via nss sulfate and excess (ex) chloride), marine source influences (via the marine biogenic component of nss sulfate, sea-salt (ss) sodium, and ex chloride) and terrestrial source influences (via calcium and ammonium) from the present back to A.D. 674. We believe that contained within these records are signals which allow differentiation and environmental characterization of climatic events that in most cases can be directly linked to changes in source and/or atmospheric circulation. The time period investigated (A.D. 674-1985)

\footnotetext{
${ }^{1}$ Glacier Research Group, Institute for the Study of Earth, Oceans and Space, University of New Hampshire, Durham. ${ }^{2}$ Also at Department of Mathematics, University of New Hampshire, Durham.

${ }^{3}$ Cold Regions Research and Engineering Laboratory, Hanover, New Hampshire.

${ }^{4}$ Laboratoire de Glaciologie et Geophysique de l'Environnement, St.-Martin-D'Hères, France.

${ }^{5}$ Department of Glaciology, Geophysical Institute, University of Copenhagen, Denmark.
}

Copyright 1993 by the American Geophysical Union.

Paper number 93JD01085.

0148-0227/93/93JD-01085\$05.00 incorporates climate events which serve as our most recent analogs for conditions cooler and warmer than the present century: the little ice age (LIA) and medieval warm period (MWP), respectively [Lamb, 1982; Grove, 1988].

\section{Approach}

The glaciochemical time series presented were sampled continuously at a mean interval of 1.94 years and analyzed under stringent procedures described elsewhere [Mayewski et al., 1987]. Dating of these series (via annual layer counting (e.g., stratigraphy, stable isotopes, chemistry, electrical conductivity, particles) and volcanic and radionuclide event histories) resulted in a chronology which departs by $<1 \%$ in age, at any level, from other ice core records developed in Greenland [Hammer et al., 1978, 1980; Hammer, 1984; Clausen and Hammer, 1988; Langway et al., 1988].

The resulting time series (Figure 1), like other records covering this period [Lamb, 1982; Grove, 1988], display obvious time-varying means and sporadic events which complicate statistical analysis. Furthermore, nonuniform sampling in time inherent in ice core series (due to variations in accumulation rate which cannot always be accounted for in sampling length) further contributes to the nonstationary behavior and precludes most of the standard techniques of time series analysis (e.g., Fast Fourier Transforms (FFTs) and "Box and Jenkins" techniques) which assume uniform sampling protocols.

The analytical procedures reported here are based on the assumption that individual records are realizations, $\left\{x\left(t_{i}\right): i=1, \ldots, N\right\}$ of stochastic processes of the form $X(t)=S(t)+Y(t)$, where $S$ represents a sporadic point process generated by nonclimatic factors (e.g., volcanic activity, biomass burning events) and $Y$ is either Gaussian, of the form

$$
Y(t)=\mu(t)+H(t)+Z(t),
$$

or log-Gaussian, of the form

$$
Y(t)=\exp [\mu(t)+H(t)+W(t)] .
$$

Here $\mu$ represents the deterministic, aperiodic component of the mean of $Y$ (or $\log (Y)$ ), while $H, Z$, and $W$ represent, in general, nonstationary, zero mean, oscillatory processes 


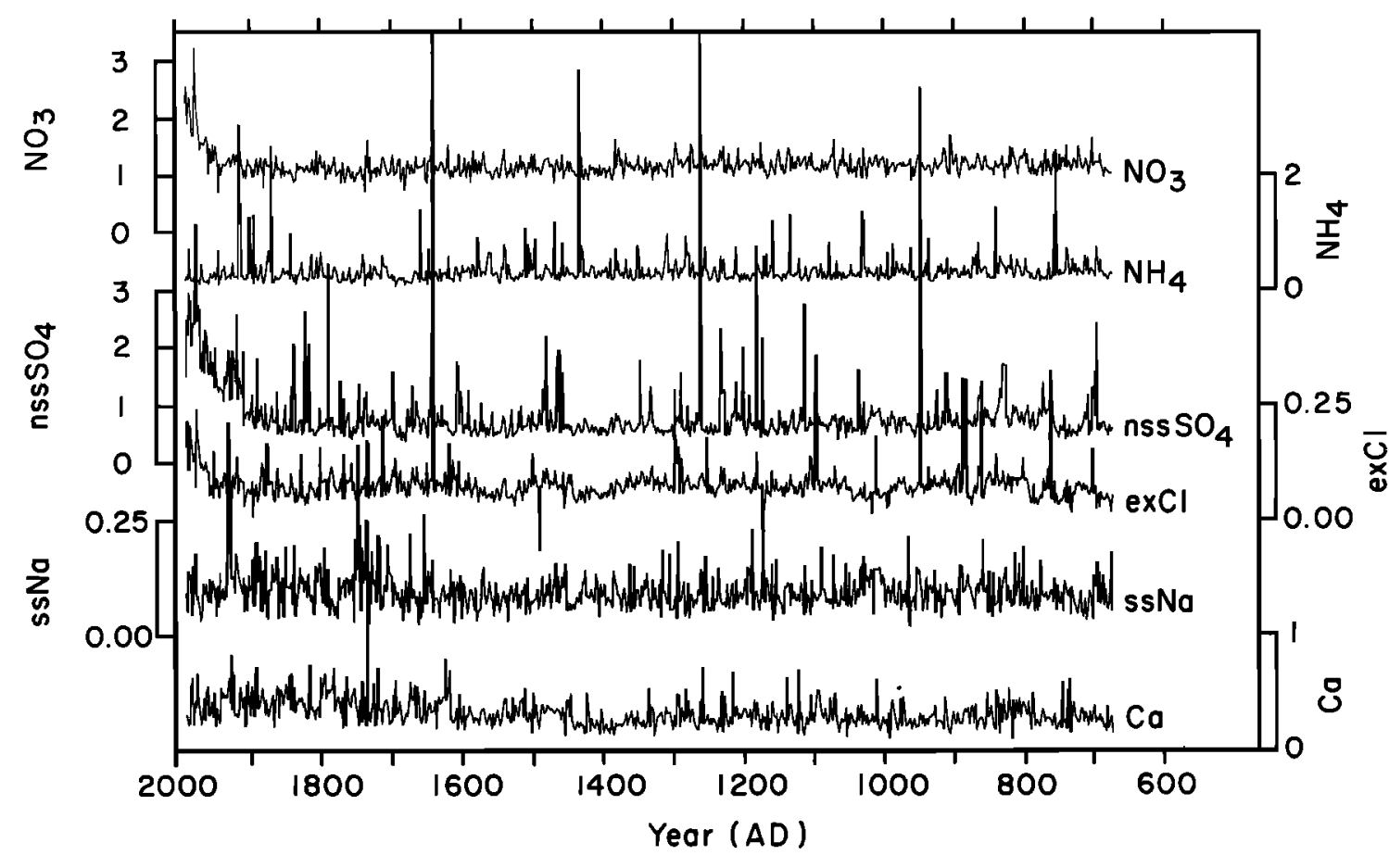

Fig. 1. Original biannuel time series; all values in $\mu \mathrm{eq} / \mathrm{L}$. Both non-sea-salt (nss) sulfate and excess chloride were determined on the basis of ss sodium. Sea-salt sodium was derived on the basis of a terrestrial ratio of sodium to calcium equivalent to 0.1 (by weight) estimated from several high-resolution snowpit studies.

[Priestley, 1988]. The "harmonic component" $H$ represents a finite sum of piecewise sinusoids, while the residual Gaussian processes $Z$ and $W$ are assumed to have continuous spectra without significant line spectral components.

The Gaussian model (equation (1)) is typical of processes of physical and/or chemical origin in which the signal is derived from the sum of a number of independent factors. The log-Gaussian model (equation (2)) provides a better description for those processes in which the signal is generated by a product of independent factors, such as some of biotic origin, in which exponential growth or decay is an important component. The calcium, ss sodium, nitrate and ex chloride series were modeled by equation (1) and the nss sulfate and ammonium series by equation (2). In each instance the choice of model form was based on the analysis of the residuals (e.g., probability plots) following the model estimation procedure described below.

The identification and estimation of the time series models began with the extraction of the nonclimate-related events, $s$, identified with the sporadic process, $S$, and least squares estimation of the mean, $\mu$, by a continuous piecewise linear function, $m$. The identification of sporadic events was accomplished through a recursive process of residual analysis following preliminary model constructions in which trends and harmonic components (treated as stationary components in the preliminary models) were removed. Based on the model assumptions, the residuals should be approximately normally distributed and display a linear normal probability plot. Observations were assigned to $S$ if their removal improved the linear fit of the residual probability plots. The cycle was repeated until the linear fit of the residual probability plot was maximized.

This provided estimates, $y=x-s$ and $h+z=x-$ $s-m($ or $h+w=\log (x-s)-m$ ) of the process $Y$ and the trend-free process $H+Z$ (or $H+W$ ). The results of these two procedures are summarized in Table 1 and Figure 2 . It is possible that some of the changes in the mean are, in reality, the result of low-frequency periodicities which are undetectable in our records. This possibility will be reconsidered when longer series are available.

The third stage of the analysis focused on the harmonic structure of the trend-free series $H+Z(H+W)$. The literature provides little guidance in the identification of nonstationary harmonics, especially given the nonuniform sampling present in the series. Our approach is to investigate the series for periodicities using two distinct procedures based on the Lomb algorithm for harmonic analysis of nonuniformly sampled series (phase-independent maximum likelihood estimation of sinusoidal components) [Lomb, 1976; Scargle, 1982; Horne and Baliunas, 1986] and to rely on extensive simulations to estimate the significance of conclusions deduced from them.

Harmonic behavior in the trend-free series was explored graphically using a form of "evolutionary spectral analysis" [Priestley, 1988] based on a two-dimensional version of the Lomb algorithm. This allows a global view of harmonic structure (e.g., shift, trend, drift). The estimated evolutionary spectra are shown in Plate 1 . The graphical results were confirmed by the normal Lomb spectral estimator followed by an estimation of the temporal distribution of spectral power in the series at the frequency of interest by estimation of the Lomb spectra for stepwise determined initial and final segments of the series. A significant sinusoidal factor was extracted from the contiguous time interval over which the spectral power (as estimated by the stepwise procedure) was maximized (Table 2). While the evolutionary spectrum (Plate 1) tends to underestimate the duration of harmonic signals, simulations show that the stepwise approach (Table 
TABLE 1. Summary of Sporadic Outliers and Trend(s) per Series

\begin{tabular}{|c|c|c|c|c|}
\hline Series & No., $\mathbf{S}$ & $\begin{array}{c}\sim \mathrm{t} \\
\text { Value }\end{array}$ & Trend, $\mu \mathrm{eq} / \mathrm{yr}$ & $\begin{array}{c}\text { Time Period, } \\
\text { Years A.D. }\end{array}$ \\
\hline \multirow[t]{2}{*}{$\mathrm{NO}_{3}$} & 20 & 28.4 & $(+2.7 \pm 0.2) \times 10^{-2}$ & [1937-1985] \\
\hline & & 5.0 & $(-6.8 \pm 3.0) \times 10^{-5}$ & {$[674-1937]$} \\
\hline $\log \mathrm{NH}_{4}$ & 46 & 5.0 & $(-1.9 \pm 0.7) \times 10^{-4}$ & [674-1985] \\
\hline \multirow[t]{4}{*}{$\log \mathrm{nssSO}_{4}$} & 72 & 28.7 & $(+1.2 \pm 0.1) \times 10^{-2}$ & [1867-1985] \\
\hline & & 2.5 & $(+1.03 \pm 1.02) \times 10^{-4}$ & [1153-1867] \\
\hline & & 8.0 & $(-7.6 \pm 2.4) \times 10^{-4}$ & [811-1153] \\
\hline & & 6.5 & $(+2.5 \pm 1.0) \times 10^{-3}$ & \\
\hline \multirow[t]{3}{*}{ ex Cl } & 34 & 18.9 & $(+6.3 \pm 0.8) \times 10^{-3}$ & [1946-1985] \\
\hline & & 4.1 & $(-1.7 \pm 1.1) \times 10^{-5}$ & [829-1946] \\
\hline & & 7.3 & $(+3.7 \pm 1.3) \times 10^{-4}$ & {$[674-829]$} \\
\hline \multirow[t]{3}{*}{ ss NA } & 26 & 3.2 & $(-7.5 \pm 5.6) \times 10^{-4}$ & [1914-1985] \\
\hline & & 7.1 & $(+1.8 \pm 0.6) \times 10^{-4}$ & [1587-1914] \\
\hline & & -1.1 & $(-8.5 \pm 19.1) \times 10^{-6 *}$ & [674-1587] \\
\hline \multirow[t]{3}{*}{$\mathrm{Ca}$} & 56 & 4.6 & $(-6.4 \pm 3.3) \times 10^{-4}$ & [1846-1985] \\
\hline & & 14.3 & $(+3.7 \pm 0.6) \times 10^{-4}$ & [1391-1846] \\
\hline & & 2.0 & $(-3.2 \pm 3.9) \times 10^{-5 *}$ & [674-1391] \\
\hline
\end{tabular}

Column 2 gives the number of observations judged to be of nonclimatic origin and associated with the sporadic process $S$; column 3 indicates the approximate $t$ statistic associated with the trend coefficient (values are approximate due to correlations among the series observations); column 4 indicates Bonferroni joint approximate $95 \%$ confidence intervals for the slopes of the estimated piecewise linear mean of each series. Confidence intervals are conditional upon the estimated "break points" and approximate due to correlations among the observations; column 5 indicates the estimated time interval over which the series follows the indicated trend. The "break points" separating the trend intervals were estimated by least squares minimization.

*Not jointly significant at the $95 \%$ level of significance.

2) tends toward overestimation and thus is likely to provide conservative outer bounds for the active interval of the given periodicity.

The estimate, $h$, of the process, $H$, obtained through the above process was combined with the previously identified first-order components to form an estimate of the "signal," $x_{s i g}$ (Figure 3), contained in the original series

$$
x_{s i g}=s+m+h\left[\text { or } x_{s i g}=s+\exp (m+h)\right] .
$$

The total variance explained in the original series by $x_{s i g}$ is $65 \%$ (nitrate), $85 \%$ (ammonium), $93 \%$ (nss sulfate), $96.6 \%$ (ex chloride), $54 \%$ (ss sodium), and $68 \%$ (calcium).

The residual series, $z=x-x_{s i g}$ (or $w=\log (y)-m-$ $h$ ), exhibit very strong Gaussian characteristics (Figure 4) in conformance with the basic model assumptions. These series will, at a later date, be subject to spectral analysis in order to determine their second-order continuous spectral characteristics.

\section{Chemical Species Signal Characteristics and Sources}

There is strong evidence suggesting that many of the processes controlling the Earth system, in particular climate, have complex structures (e.g., cycles and nonlinearities which can turn on and off on the scale of years to thousands of years). To investigate these structures, we need paleoclimatic records that can "sense" such complexity. As a test of this sensitivity, the signal characteristics generated in this study are compared to a temperature record (Figures 2-3 and Plate 1) that broadly characterizes the source and transport regions feeding central Greenland. Trend(s) and sporadic events (Table 1 and Figure 2) in the series are investigated first.

\section{Nitrate: Trend(s) and Sporadic Events}

Although the exact sources of nitrate are not fully understood, it is expected that by analogy with south polar precip- itation, lightning source nitrate, $\mathrm{NO}_{0}$ produced from $\mathrm{N}_{2} \mathrm{O}$ oxidation in the lower stratosphere, galactic cosmic rays, and/or surface sources [Legrand and Kirchner, 1990] may be important in Arctic precipitation. In addition, the recent dramatic increase (Figure 2) observed in Greenland has previously been attributed to anthropogenic sources [Neftel et al., 1985; Mayewski et al., 1986, 1990b]. Since the preanthropogenic trend in our record is best represented by the Gaussian model and thus not exponential, we assume that the dominant source for this portion of the record is nonbiogenic and therefore not substantially contributed to by biogenic (surface) sources. There is no apparent pattern to the distribution of sporadic terms, and thus it is not possible to assign a unique source to these events.

\section{Ammonium: Trend(s) and Sporadic Events}

Background levels of ammonium decline exponentially to the present (after model 2), suggesting a decrease from warm to cooler portions of the record of biogenic influences to the region. Since $\mathrm{NH}_{3}$ concentrations tend to be highest near continents [Logan, 1983], the decrease suggests that source area extent over the continents and/ or the processes driving ammonium production or transport declined. Since modern levels of ammonium do not return to those characteristic of warmer periods, the influence of some form of anthropogenic forcing may be suspected (e.g., removal of ammonium by reaction with increased levels of anthropogenically derived nss sulfate and nitrate [Langford and Fehsenfeld, 1992]). Ammonium outliers in ice core records from central Greenland have been interpreted as northern high-latitude biomassburning events [Legrand et al., 1992; Taylor et al., 1993]. These events are present throughout the entire record except from $\sim 1650$ to 1750 , during which time biomass extent or burn potential would have been reduced in response to lower (LIA) temperatures and consequent reduction in biomass. 

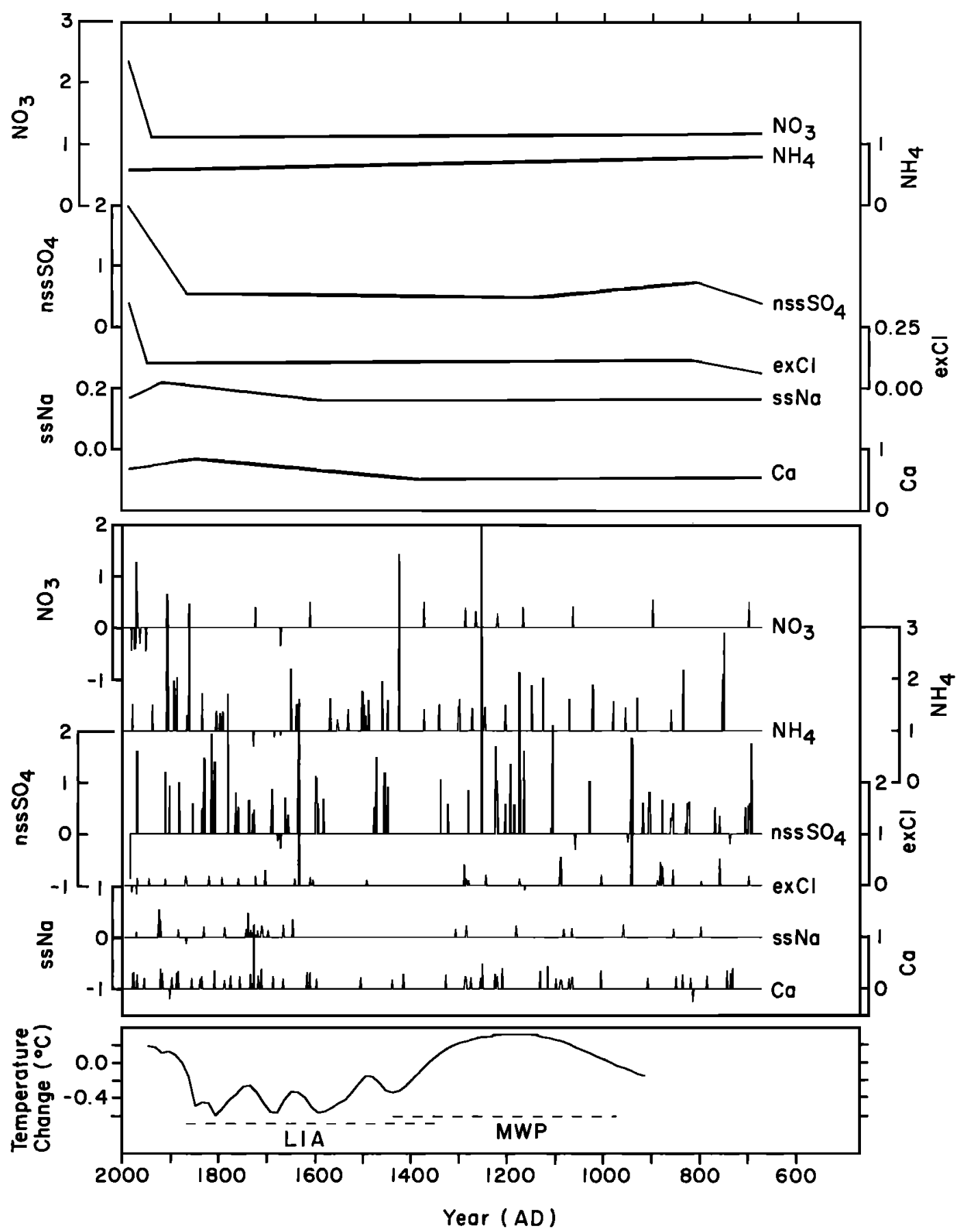

Fig. 2. Trend(s) (upper sequence) and sporadic events (lower sequence), all in $\mu \mathrm{eq} / \mathrm{L}$, plus temperature change in degrees Celsius relative to the mean of $\sim 1900$ produced from a variety of western European and eastern North American proxy records [Houghton et al., 1990; Eddy et al., 1991]. Approximate time ranges for the little ice age and medieval warm period are indicated.

Non-Sea-Salt Sulfate: Trend(s) and Sporadic Events

Several major trends are identifiable in the nss sulfate series, including a previously identified rise due to anthropogenic sources [Neftel et al., 1985; Mayewski et al., 1986, $1990 \mathrm{~b}$ ]. Background levels of nss sulfate are the product of volcanic and/or biogenic (marine and/or terrestrial) sources. Since the log-Gaussian model best fits the series, this favors a biogenic influence. This is further corroborated by the lack of correlation between outliers (volcanic events) in this series and changes in trend. Since preanthropogenic, terrestrial biogenic sources of $S$ gases would have been most extensive during the warmest portion of the record (MWP), the increase in trend during cooler periods suggests that marine sources of $\mathbf{S}$ gases are the primary contributor to trend during cool periods. (Hence temperatures, nutrients, sea ice extent [Gibson et al., 1990], and/or other conditions during cool periods were more suited to the growth of surface marine S-gas-producing organisms). The potential influence of individual volcanic events on temperature (via radiation shielding by $\mathrm{H}_{2} \mathrm{SO}_{4}$ ) is well documented [Mass and Schneider, 1977; Taylor et al., 1980; Self et al., 1981; Kelly and Sear, 1984]; however, based on the frequency and timing of these events in our record, they could not have contributed significantly to longer-term ( $\sim 10^{1}$ to $>10^{2}$ years) changes in temperature. 


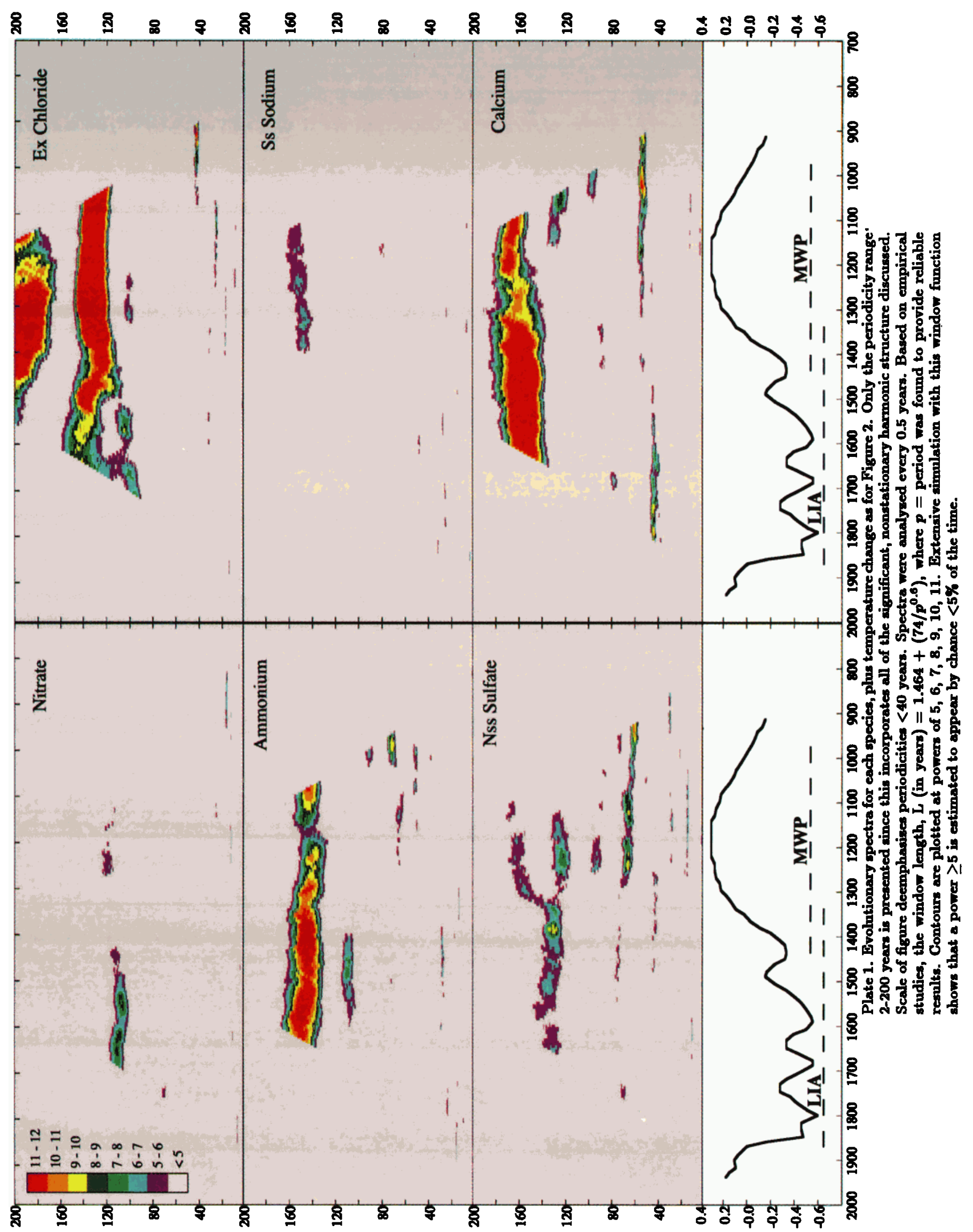


TABLE 2. Period, Species, Estimated Interval of Activity (Time Range), the Significance (p Value Estimated by Simulation Using Two-Segment Lomb Analysis) and Percent Variance over the Active Interval Associated with the Given Periodicity

\begin{tabular}{clrlr}
\hline $\begin{array}{c}\text { Period, } \\
\text { Years }\end{array}$ & Species & $\begin{array}{r}\text { Time Range, } \\
\text { Years A.D. }\end{array}$ & $\begin{array}{l}\text { Signifi- } \\
\text { cance }\end{array}$ & $\begin{array}{c}\text { Variance, } \\
\%\end{array}$ \\
\hline 455 & exCL & $674-1985$ & $<0.05$ & 2.4 \\
204 & exCL & $774-1877$ & $<0.001$ & 7.3 \\
168 & ssNa & $952-1335$ & $<0.01$ & 8.5 \\
156 & $\mathrm{Ca}$ & $1105-1795$ & $<0.001$ & 12.8 \\
143 & $\mathrm{NH}_{4}$ & $674-1768$ & $<0.001$ & 7.3 \\
135 & nssSO $_{4}$ & $1087-1687$ & $<0.10$ & 7.1 \\
130 & exCl & $674-1609$ & $<0.001$ & 13.4 \\
112 & $\mathrm{NO}_{3}$ & $794-1895$ & $<0.05$ & 3.2 \\
73 & nss4SO $_{4}$ & $674-1902$ & $<0.01$ & 4.0 \\
64 & nssSO $_{4}$ & $674-1985$ & $<0.01$ & 2.5 \\
54 & $\mathrm{Ca}$ & $674-1655$ & $<0.01$ & 6.3 \\
43 & $\mathrm{Ca}$ & $766-1985$ & $<0.05$ & 3.3 \\
31 & exCl $_{14}$ & $\mathbf{8 6 7 - 1 9 8 5}$ & $<0.10$ & 4.0 \\
14 & nssSO $_{4}$ & $935-1824$ & $<0.05$ & 5.3 \\
12 & $\mathrm{NO}_{3}$ & $799-1311$ & $<0.10$ & 8.1 \\
10 & $\mathrm{NH}_{4}$ & $724-1829$ & $<0.05$ & 3.2 \\
7 & exCl & $842-1905$ & $<0.10$ & 4.4 \\
6 & ssNa $_{5}$ & $700-1868$ & $<0.05$ & 3.0 \\
5 & ssNa & $1765-1985$ & $<0.01$ & 15.2 \\
\hline
\end{tabular}

\section{Excess Chloride: Trend(s) and Sporadic Events}

The most notable trend in excess chloride is an increase since 1946 , possibly in response to increases in anthropogenically derived $\mathrm{HNO}_{3}$ and $\mathrm{H}_{2} \mathrm{SO}_{4}$, which aid in the volatilization of $\mathrm{HCl}$ from sea-salt aerosol [Eriksson, 1959]. During the preanthropogenic portion of the record, the highest background levels appear in the early $800 \mathrm{~s}$, after which levels decline slightly. This portion of the ex chloride trend is similar to the trend in nss sulfate for the same period, as might be expected for two reaction-related marine source indicators. Outliers of ex chloride are believed to represent periods of intense volatilization or long-traveled (fractionated) marine aerosols.

\section{Sea-Salt Sodium: Trend(s) and Sporadic Events}

Since meteorological conditions over Greenland are largely affected by the transport of low-pressure systems from lower latitudes [Barry and Kiladas, 1982] and the primary source for ss sodium during cooler periods is probably from an ice-free (lower latitude) ocean, increases in ss sodium trend and outliers define a period (1587-1914) when inflow from lower latitudes was more intense. This is consistent with studies suggesting that the LIA was a period of increased warm air transport [Crowley, 1984] and, in general, meridional flow [Fritts et al., 1979] to Greenland. The return to pre-1587 ss sodium levels by 1914 may provide an indicator for measuring the end of LIA-style marine transport to central Greenland.

\section{Calcium: Trend(s) and Sporadic Events}

Trends in calcium since the end of the MWP are broadly inverse to temperature, and while outliers of calcium appear throughout the entire record, they are less frequent during the onset of the rise in background calcium. Since terrestrial dust is the primary source of calcium to this site [Mayewski et al., 1990a], increased levels imply more intense circulation over continental regions and/or the presence of more easily erodable terrain. The early LIA is assumed to have been relatively cold and moist in some regions [LaMarche, 1974], while evidence from China [Zheng and Feng, 1986] suggests that latter portions of the LIA were dustier. An increase in trend, but not in outliers, at A.D. 1391 may be an indication of the beginning of cold, moist conditions (exposed, yet rel-

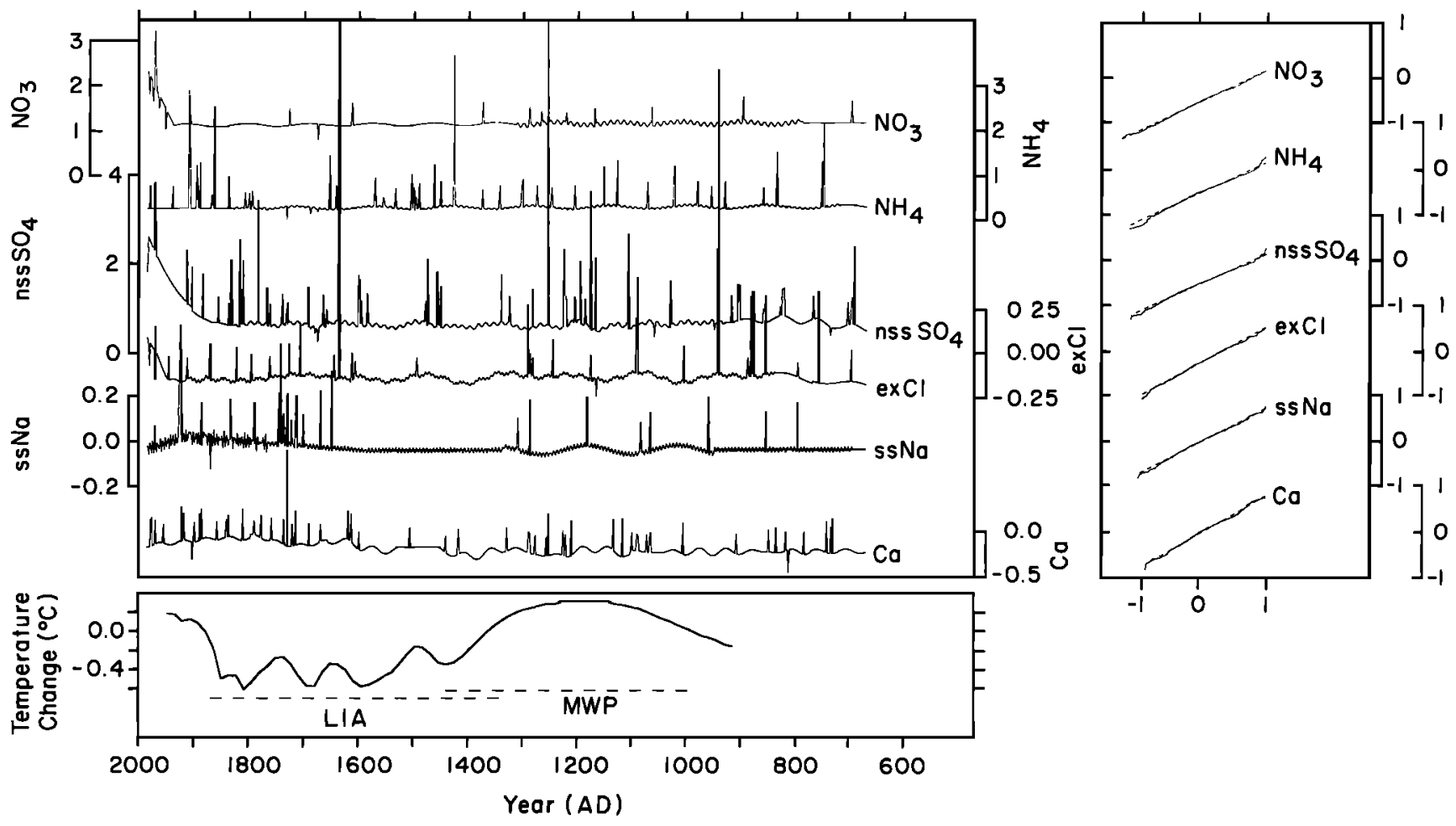

Fig. 3. The "signal" for each species developed from a composite of trend(s), outliers, and harmonics (adjusted for nonstationarity, Table 2) plus temperature change as for Figure 2. The normalized residual for each series is plotted as a probability plot relative to Gaussian noise. The dotted line is theoretical and the solid is observed. 
atively stabilized terrain). Continued increase in trend plus outliers at A.D. 1600 suggests colder and/or drier conditions. By A.D. 1846, warm (decrease in trend) and dry conditions (maintained frequency of outliers) appear to dominate the continental sources feeding central Greenland, signaling an end to the LIA on land.

With trend(s) and sporadic events removed, the second stage of "signal characterization" focuses on harmonic structure. (Table 2 and Plate 1 provide two complementary views of harmonic structure.)

\section{Nitrate: Harmonics}

Nitrate displays two significant periodicities: 112 and 12 years. Power at the 112-year period extends through most of the record, although it is strongest from the mid-1400s to 1895 (Plate 1), during the cooler portion of the record. The 12-year period appears most intensely in the earlier (warmer) part of the record. Although the 12-year periodicity in nitrate is close to the 11-year sunspot cycle and nitrate has a solar-modulated source in the upper atmosphere [Nicolet, 1975], the significance at this periodicity is relatively weak $(<0.10)$. Further, other species in this study, with no known solar sources, also display periodicities which are close to solar-associated periodicities. Therefore our investigation cannot provide a resolution to the controversy surrounding the link between solar activity and nitrate in snow [Zeller and Parker, 1981]. The clear distinction between the harmonic composition of warm versus cool portions of the record indicates, however, that forcing influences on transport and/or source that are linked to climate change do exist in the nitrate record.

\section{Ammonium: Harmonics}

Ammonium has at least two strong periodicities, 143 and 10 years. The 143 -year periodicity appears to be least robust from $\sim 1100$ to $\sim 1250$ (close to the postulated height of the MWP, Plate 1), and the 10-year periodicity (Table 2) may actually reflect some combination of nonstationary periodicities in the range several to $<30$ years, which appear to be most persistent during the LIA portion of the record (Plate 1). The ammonium harmonic signal provides evidence of an undetermined cause of forcing of continental source air masses to central Greenland and/or of the degradation of continental biomass. Neither the 143-year nor $10-$ year periodicity persists to the present, suggesting potential anthropogenic masking for the type of signals present during the MWP.

\section{Non-Sea-Salt Sulfate: Harmonics}

Several periodicities are present in the nss sulfate series: $14,64,73$, and 135 years. Since it is unlikely that any harmonic structure is induced by volcanic input, they represent modulation of the nss sulfate derived from marine and/or terrestrial biogenic sources. Further, there is a coincidence between the timing of the strongest portion of the shorterperiod signals and the maximum of the MWP (Plate 1), when terrestrial and/or marine biogenic sources could be involved. Since the 135 -year signal persists during warm and cold times, it is more likely reflecting marine biogenic sources that would be important even when terrestrial sources were restricted by temperature.

\section{Excess Chloride: Harmonics}

Excess chloride displays the broadest range of periodicities of the species analyzed, namely, 7, 31, 130, 204, and 455 years. Due to the length of our record, the two longestperiod signals cannot be adequately investigated. The 130year periodicity is notable because it is fairly close to the 135-year nss sulfate periodicity, as might be expected for at least some of the periodic structure of these two mainesource species. Both signals persist into the $1600 \mathrm{~s}$, but the nss sulfate signal does not start until 1087. Excess chloride periodicities do not, however, appear to reflect just $\mathrm{H}_{2} \mathrm{SO}_{4}$-induced volatilization of $\mathrm{HCl}$ as was suggested from a comparison of their trends but perhaps also reflect marine chloride produced under other conditions conducive to fractionation of sea-salt aerosols (e.g., evaporation, decrease in storminess). The 31-year ex chloride signal extends through most of the record (Table 2) but is strongest during the MWP (Figure 2). Similar periodicity has been identified in Sahelian drought (31 years) [Faure and Gac, 1981], Lapland tree ring (32 years) [Siren, 1961], and European weather (34 years) [Brückner, 1890] records. By association with our 31year signal these records may be linked to provide a spatial view of marine air mass transport. The 7-year periodicity in ex chloride may be associated with the 5- and 6-year periodicities discussed under ss sodium.

\section{Sea-Salt Sodium: Harmonics}

Sea-salt sodium displays harmonic structure at periods of 168,6 , and 5 years. The 168 -year periodicity in ss sodium is strongest during the MWP portion of the record. A 167year period was identified in ice cores from Greenland and Arctic Canada and presumed to have a solar-climate association [Fisher, 1982]. Tracking this signal could provide a record of the solar modulation of marine air mass transport emanating from regions that are sources to central Greenland during warm periods (perhaps local marine sources). Both 5- and 6-year periodicities are differentiable in the ss sodium record. The 5-year period appears to dominate the last $\sim 200$ years of record. While there is no definitive evidence that these periodicities are linked to a partic alar process, they are in the range of periodicity of regional scale marine air mass oscillations such as the North Atlantic Oscillation (the interannual variation of pressure over Iceland relative to the Azores and northwest Europe [Walker and Bliss, 1932]), which could be "felt" in central Greenland and therefore hold promise for tracking such an event.

\section{Calcium: Harmonics}

Calcium displays periodicities at 156,54 , and 43 years. The 156-year period in calcium extends through the record but appears to weaken near the end of the MWP and then strengthen during the LIA (Plate 1). With longer records it may be possible to investigate such "reorganizations." The 43-year periodicity is strongest during the LIA, while strength in the 54-year signal is skewed toward the warmer portion of the record. A 45-year period was previously identified as an indicator of storminess and higher tides in the Arctic [Fairbridge and Hillaire-Marcel, 1977]. Periodicities in the calcium series provide evidence of some undetermined cause of modulation affecting continental dust sources or transport characteristics of air masses emanating from such sources. 


\section{Concluding Remarks}

The statistical techniques presented provide a new quantitative approach to the analysis and interpretation of environmental time series. Based on a consistently conservative approach and extensive simulation to estimate null distributions, we are confident that while our techniques are "exploratory," future analyses will not substantially alter our findings. The fact that the same signal structure is not present in every chemical series suggests that the entire suite of series is not dependent on a single factor such as accumulation rate or postdepositional alteration. In fact, each series provides an independent interpretation, which together provide a new view of environmental change.

The results described and graphically summarized in the form of "signals" (Figure 3) provide a high-precision, joint confidence technique that allows a description of change, in source and/or circulation style, via the investigation of sporadic events, means, and harmonic structure. It is clear that even relatively minor climatic events such as the IIA and MWP are sensitively recorded by differences in the signal characteristics of the six species analyzed.

Based on changes in trend, continental air masses (via calcium) appear to reflect the onset of LIA conditions $\sim 200$ years before (1391 compared to 1587) and to reflect the end of the LIA 70 years earlier (1846 compared to 1914) than marine source air masses (via ss sodium). Evidence of such lagging will be useful for elucidating the processes controlling change and/or the continental versus marine responses to change. Further, trends in nitrate, nss sulfate, ex chloride, and ammonium have not returned to MWP conditions since the end of the LIA due to anthropogenic influences on the levels of these species. Investigation of outlier distribution provides information concerning events such as volcanic activity, biomass burning, storminess, and aridity.

Periodic forcing of biogenic (via ammonium) and dust (via calcium) components of continental air masses and biogenic (via nss sulfate), sea-salt (via ss sodium), and gaseous (vis ex chloride) components of marine air masses can be tracked using ice core records. Notably, nonstationarities in the periodicity of these species plus nitrate parallel the timing of the LIA and MWP, providing potential for using such records to understand the complex processes that produce climate change. Although the underlying cause of harmonic variation (whether due to "beats" arising from the combinations of periodic components, modulation by nonlinear processes, or other mechanisms) cannot be determined from this short record or our current state of knowledge, the sensitivity expressed by ice core records suggests that in the future the answers to such questions may be found in the detailed signal analysis of longer records now being recovered from central Greenland.

Acknowledgments. We thank our colleagues from the U.S. Greenland Ice Sheet Project 2 (GISP 2) and the European Greenland Ice Core Program (GRIP), the Polar Ice Coring Office (University of Alaska), the GISP 2 Science Management Office (University of New Hampshire), and the 109th Air National Guard for their support. R. Alley, T. Gow, M. Ram, and K. Taylor contributed extensively to the dating of the record. Several individuals contributed to this work, including B. Lyons, K. Welch, C. Kingma, C. Buck, D. Barrett, Q. Yang, L. Fosberry, Z. Tao, S. Drummey, and C. Weir. European coauthors were funded by the Commission of European Communities. The work presented was funded by the United States National Science Foundation.

\section{References}

Barry, R. G., and G. N. Kiladas, Climatic characteristics of Greenland, in Climatic and Physical Characteristics of the Greenland Ice Sheet, parts I and II, edited by U. Radok et al., pp. 7-34, Cooperative Institute for Research in Environmental Science, Boulder, Colo., 1982.

Brückner, E., Klimaschwankungen seit 1700 nebst Bemerkungen über die Klimaschwankungen der Diluvialzeit, Geogr. Abh. Herausgeben A. Penck, 4, 325, 1890.

Clausen, H. B., and C. U. Hammer, Glaciological investigations in the Crête area, central Greenland: A search for a new deepdrilling site, Ann. Glaciol., 10, 16-22, 1988.

Crowley, T. J., Atmospheric circulation patterns during glacial inception: A possible candidate, Quat. Res., 21, 105-110, 1984.

Eddy, J. A., R. S. Bradley, and T. Webb III, Earthquest, OIES Publ. 5(1), University Corporation for Atmospheric Research, Boulder, Colo., 1991.

Eriksson, E., The yearly circulation of chloride and aulfur in nature: Meteorological, geochemical and pedological implications, 1, Tellus, 11, 375-403, 1959.

Fairbridge, R., and C. Hillaire-Marcel, An 8,000-yr paleeoclimatic record of the 'Double-Hale' 45-yr solar cycle, Nature, 268, 413$416,1977$.

Faure, H., and J. Y. Gac, Will the Sahelian drought end in 1985?, Nature, 291, 475-478, 1981.

Fisher, D. A., Carbon-14 production compared to oxygen isotope records from Camp Century, Greenland and Devon Island, Canade, Clim. Change, 4, 419-426, 1982.

Fritts, H. C., G. R. Lofgren, and G. A. Gordon, Variations in climate aince 1602 as reconstructed from tree rings, Quat. Res., 21, 18-46, 1979.

Gibson, J. A. E., R. C. Garrick, H. R. Burton, and A. R. McTaggart, Dimethylaulfide and the alga Phaeocystis pouchetii in Antarctic cosstal waters, Mar. Biol., 104, 339-346, 1990.

Grove, J. M., The Little Ice Age, 498 pp., Routledge and Kegan Pavl, Boston, Mass., 1988.

Hammer, C. U., Traces of Icelandic eruptions in the Greenland Ice Sheet, Jokull, 34, 51-65, 1984.

Hammer, C. U., H. B. Clausen, W. Dansgaard, N. Gundestrup, S. J. Johnsen, and N. Reeh, Dating of Greenland ice cores by flow models, isotopes, volcanic debris, and continental duat, $J$. Glaciol., 20, 3-26, 1978.

Hammer, C. U., H. B. Cleusen, and W. Dansgaard, Greenland ice sheet evidence of post-glacial volcanism and its climstic impact, Nature, 288, 230-235, 1980.

Horne, J. H., and S. L. Baliunes, A prescription for period analysis of unevenly sampled time series, Astrophys. J., 302, 757$763,1986$.

Houghton, J. T., G. J. Jenkins, and J. J. Ephraum (Eds.), Climate Change: The IPCC Scientific Assessment, 202 pp., Cambridge University Press, New York, 1990.

Kelly, P. M., and C. B. Sear, Climatic impact of explosive volcanic eruptions, Nature, 311, 740-743, 1984.

LaMarche, V. C., Paleoclimatic inferences from long tree-ring records, Science, 183, 1043-1048, 1974.

Lamb, H. H., Climate History and the Modern World, 387 pp., Methuen, New York, 1982.

Langford, A. O., and F. C. Fehsenfeld, Natural vegetation as a source or sink for atmospheric ammonia: A case study, Science, $255,581-583,1992$.

Langway, C. C., Jr., H. B. Clausen, and C. U. Hammer, An interhemispheric volcanic time-marker in ice cores from Greenland and Antarctica, Ann. Glaciol, 10, 102-108, 1988.

Legrand, M. R., and S. Kirchner, Origins and variations of nitrate in south polar precipitation, J. Geophys. Res., 95, 3493-3509, 1990.

Legrand, M., M. DeAngelis, T. Stafflebach, A. Neftel, and B. Stauffer, Large perturbations of ammonium and organic acids content in the Summit-Greenland ice core. Fingerprint from forest fires?, Geophys. Res. Lett., 19, 473-475, 1992.

Logan, J. A., Nitrogen oxides in the troposphere: Global and regional budgets, J. Geophys. Res., 88, 10,785-10,807, 1983.

Lomb, N. R., Least-squares frequency analysis of unevenly spaced data, Astrophys. Space Sci., 39, 447-462, 1976.

Mass, C., and S. H. Schneider, Statistical evidence on the influence of sunspots and volcanic dust on long-term temperature 
records, J. Atmos. Sci., 34, 1995-2008, 1977.

Mayewski, P. A., W. B. Lyons, M. J. Spencer, M. S. Twickler, B. Koci, W. Dansgaard, C. Davidson, and R. Honrath, Sulfate and nitrate concentrations from a south Greenland ice core, Science, 232, 975-977, 1986.

Mayewski, P. A., M. J. Spencer, W. B. Lyons, and M. S. Twickler, Seasonal and spatial trends in south Greenland snow chemistry, Atmos. Environ., 21, 863-869, 1987.

Mayewski, P. A., M. J. Spencer, M. S. Twickler, and S. Whitlow, A glaciochemical survey of the summit region, Greenland, $A n n$. Glaciol., 14, 186-190, 1990a.

Mayewski, P. A., W. B. Lyons, M. J. Spencer, M. S. Twickler, C. F. Buck, and $S$. Whitlow, Recent increase in nitrate concentration of Antarctic snow, Nature, 346, 554-556, 1990b.

Neftel, A., J. Beer, H. Oeschger, F. Zurcher, and R. C. Finkel, Sulphate and nitrate concentration in snow from south Greenland 1895-1978, Nature, 314, 611-613, 1985.

Nicolet, M., On the production of nitric oxide by cosmic rays in the mesosphere and stratosphere, Planet. Space Sci., 23, 637-649, 1975.

Priestley, M. B., Non-linear and Non-stationary Time Series Analysis, 237 pp., Academic, San Diego, Calif., 1988.

Scargle, J. D., Studies in Astronomical time series analysis, II, Statistical aspects of spectral analysis of unevenly spaced data, Astrophys. J., 263, 835-853, 1982.

Self, S., M. R. Rampino, and J. J. Barbera, The possible effects of large 19th and 20th century volcanic eruptions on zonal and hemispheric surface temperatures, $J$. Volcanol. Geotherm. Res., 11, 41-60, 1981.

Siren, G., Sklogsgranstallen som indikator for klimafluktuationerna i norra Fennoskandien under historisk tid, Inst. For. Fenn.
(Helsingfors) Commun., 54, 64 pp., 1961.

Taylor, B. L., T. Gal-Chen, and S. H. Schneider, Volcanic eruptions and long-term temperature records: An empirical search for cause and effect, Q. J. R. Meteorol. Soc., 196, 175-199, 1980.

Taylor, K., P. A. Mayewski, J. Palais, and G. Lamorey, Fire history of the boreal forest as recorded in the Greenland Ice Sheet, submitted to Quat. Res., 1993.

Walker, G. T., and E. W. Bliss, World weather V, Mem. R. Meteorol. Soc., 4, 53-84, 1932.

Zeller, E. J., and B. C. Parker, Nitrate ion in Antarctic firn as a marker for solar activity, Geophys. Res. Lett., 8, 895-898, 1981.

Zheng, S., and L. Feng, Historical evidence of climatic instability above normal in cool periods in China, Sci. Sin. Ser. B, 29, 441-448, 1986.

K. K. Ferland, P. A. Mayewski, L. D. Meeker, M. C. Morrison, M. S. Twickler, and S. I. Whitlow, Glacier Research Group, Institute for the Study of Earth, Oceans and Space, University of New Hampshire, Durham.

D. A. Meese, Cold Regions Research and Engineering Laboratory, Hanover, New Hampshire.

M. R. Legrand, Laboratoire de Glaciologie et Geophysique de l'Environnement, St.-Martin-D'Hères, France.

J. P. Steffensen, Department of Glaciology, Geophysical Institute, University of Copenhagen, Denmark.

(Received April 14, 1993;

revised April 14, 1993;

accepted April 16, 1993) 